\title{
Increasing incidence of parosmia and phantosmia in patients recovering from COVID-19 smell loss
}

Kathrin Ohla 1†, PhD, Maria Geraldine Veldhuizen 2†, PhD, Tomer Green 3, Mackenzie E. Hannum 4, PhD, Alyssa J. Bakke 5, PhD, Shima T. Moein 6, PhD, Arnaud Tognetti 7, PhD, Elbrich M. Postma 8, PhD, Robert Pellegrino 4, PhD, Liang-Dar Hwang 9, PhD, Javier Albayay 10, PhD, Sachiko Koyama 11, PhD, Alissa Nolden 12, PhD, Thierry Thomas-Danguin 13, PhD, Carla Mucignat-Caretta 14, PhD, Nick S. Menger 15, M.Sc., Ilja Croijmans 16, PhD, Lina Öztürk 2, PhD, Hüseyin Yanık 2, M.Sc., Denis Pierron 17, PhD, Veronica Pereda-Loth 18, PhD, Alexia Nunez-Parra 19, PhD, Aldair M. Martinez Pineda 18, M.Sc., David Gillespie 20, Michael C. Farruggia 21, M.Phil., Cinzia Cecchetto 14, PhD, Marco A. Fornazieri 22, PhD, Carl Philpott 23, MD, Vera Voznessenskaya 24, PhD, Keiland Cooper 25, Paloma Rohlfs Dominguez 26, PhD, Orietta Calcinoni 27, MD, Jasper de Groot 28, PhD, Sanne Boesveldt 29, PhD, Surabhi Bhutani 30, PhD, Elisabeth M. Weir 5, BS, Cara Exten 5, MPH PhD, Paule V. Joseph 31, PhD, CRNP, Valentina Parma 4, PhD, John E. Hayes 5*, PhD, Masha Y. Niv 3*, PhD

1 Helmut-Schmidt-University/University of the Armed Forces Hamburg, Germany

2 Mersin University, Turkey

3 The Hebrew University of Jerusalem, Israel

4 Monell Chemical Senses Center, Philadelphia, USA

5 The Pennsylvania State University, USA

6 Institute for Research in Fundamental Sciences (IPM), Iran

7 Karolinska Institutet, Stockholm, Sweden

8 Wageningen University \& Research, Netherlands

9 The University of Queensland, Australia

10 University of Trento, Italy

11 Indiana University, USA

12 University of Massachusetts, Amherst, USA

13 INRAE, France

14 University of Padova, Italy

15 University of Tübingen, Germany

16 Utrecht University, Netherlands

17 CNRS, France

18 Université Toulouse III, France

19 University of Chile, Chile

20 University College London, UK

21 Yale University, USA

22 Universidade Estadual de Londrina, Brazil

23 University of East Anglia, UK

24 Severtsov Institute of Ecology \& Evolution, Moscow, Russia

25 University of California, Irvine, USA

26 Universidad del País Vasco/Euskal Herriko Unibertsitatea, Spain

27 private practice, Italy 
medRxiv preprint doi: https://doi.org/10.1101/2021.08.28.21262763; this version posted September 8, 2021. The copyright holder for this preprint

(which was not certified by peer review) is the author/funder, who has granted medRxiv a license to display the preprint in perpetuity.

It is made available under a CC-BY-NC 4.0 International license.

28 Radboud University, Netherlands

29 Wageningen University, Netherlands

30 San Diego State University, USA

31 National Institutes of Health/ NINR/NIAAA, USA

$\dagger$ co-first authors; other authors listed by relative contributions

* co-corresponding authors:

John E. Hayes*, PhD

Sensory Evaluation Center, The Pennsylvania State University, University Park PA 16803;

College of Agricultural Sciences, The Pennsylvania State University, University Park PA 16803, 220 Erickson Food Science Building, University Park PA 16803, USA;

Email: jeh40@psu.edu, Phone: +1-814-441-4393

\section{Masha Niv*, PhD}

The Robert H. Smith Faculty of Agriculture, Food and Environment, The Hebrew University of Jerusalem, Herzl street, Rehovot 76100, Israel

Email: masha.niv@mail.huji.ac.il, Phone: +972-8-9489664

Manuscript word count: 3,328

(not including title, abstract, acknowledgment, references, tables, figure legends, supplement). 


\section{Graphical abstract}

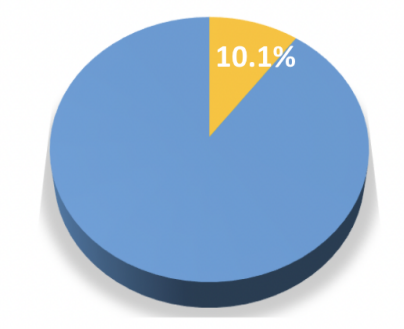

Parosmia percentage in COVID-19 patients with smell loss $(n=1468)$

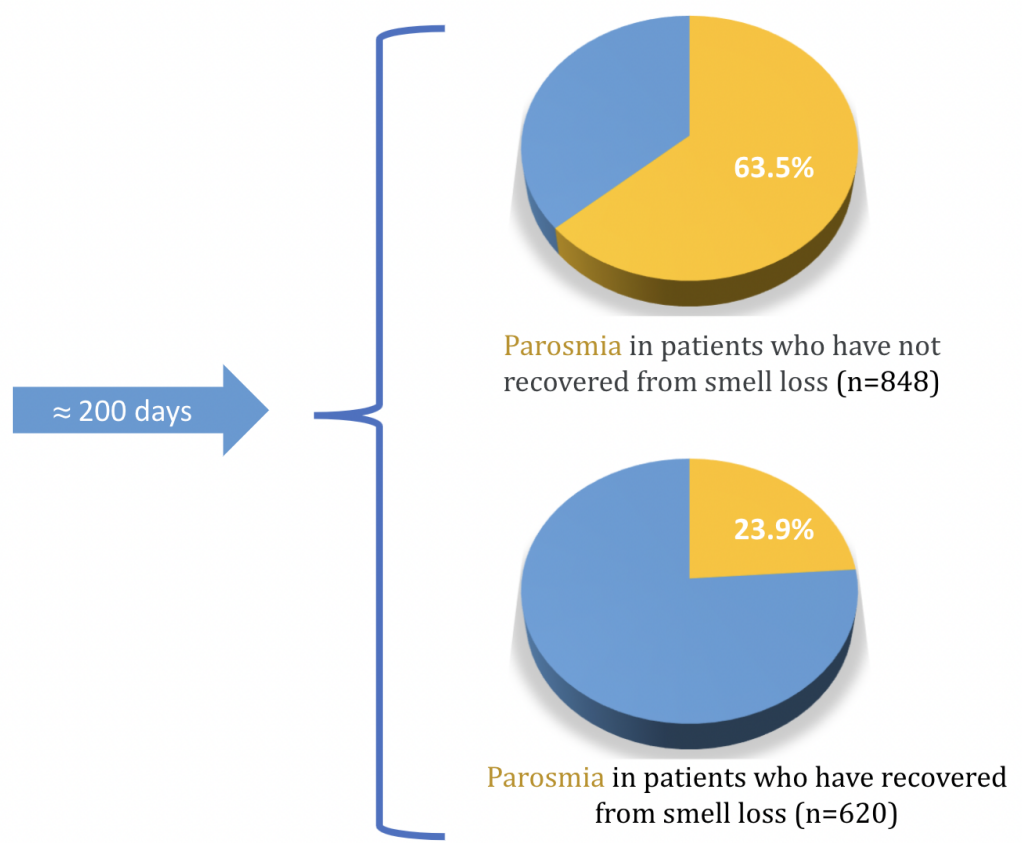

\section{Key Points}

Question: What are the characteristics of smell and taste recovery of COVID-19 patients?

Findings: In this preregistered observational study of 1,468 participants, smell loss is associated with a higher number of COVID-19 symptoms, and may persist for at least 11 months following disease onset. While a majority of participants report quantitative improvement in their ability to smell, the prevalence of parosmia and phantosmia increases substantially at follow-up. Taste recovers faster than smell, suggesting taste and smell recover separately and can be distinguished by the respondents.

Meaning: Olfactory dysfunction appears to be a component of long-COVID, with parosmia as a prominent symptom in almost half of those with smell loss. More research into treatment is needed, especially given that olfactory dysfunction is associated with depression and loss of appetite. Health professionals should be aware of these common and long lasting effects. 


\section{Abstract}

Importance: Sudden smell loss is a specific early symptom of COVID-19, with an estimated prevalence of $\sim 40 \%$ to $75 \%$. Smell impairment affects physical and mental health, and dietary behavior. Thus, it is critical to understand the rate and time course of smell recovery.

Objective: To characterize smell function and recovery up to 11 months post COVID-19 infection.

Settings, Participants: This longitudinal survey of individuals suffering COVID-19-related smell loss assessed disease symptoms and gustatory and olfactory function. Participants $(n=12,313)$ who completed an initial respiratory symptoms, chemosensory function and COVID-19 diagnosis survey (S1) between April and September 2020 and completed a follow-up survey (S2) between September 2020 and February 2021; 27.5\% participants responded $(n=3,386)$, with 1,468 being diagnosed with COVID-19 and suffering co-occurring smell and taste loss at the beginning of their illness.

Main Outcomes \& Measures: Primary outcomes are ratings of smell and taste function on a visual analog scale, and self-report of parosmia (smell distortions) and phantosmia (unexplained smells). Secondary outcomes include a checklist of other COVID-19 symptoms.

Results: On follow-up (median time since COVID-19 onset $\sim 200$ days), $\sim 60 \%$ of women and $\sim 48 \%$ of men reported less than $80 \%$ of their pre-illness smell ability. Taste typically recovered faster than smell, and taste loss rarely persisted if smell recovered. Prevalence of parosmia and phantosmia was $\sim 10 \%$ of participants in $\mathrm{S} 1$ and increased substantially in $\mathrm{S} 2: \sim 47 \%$ for parosmia and $\sim 25 \%$ for phantosmia. Persistent smell impairment was associated with more symptoms overall, suggesting it may be a key marker of long-COVID. During COVID-19 illness, the ability to smell was slightly lower among those who did not recover their pre-illness ability to smell at S2.

Conclusions and Relevance: While smell loss improves for many individuals who lost it due to COVID-19, the prevalence of parosmia and phantosmia increases substantially over time. Olfactory dysfunction is also associated with wider COVID-19 symptoms and may persist for many months after COVID-19 onset. Taste loss in the absence of smell loss is rare. Persistent qualitative smell symptoms are emerging as common long term sequelae; more research into treatment options is strongly warranted given that conservative estimates suggest millions of individuals may experience parosmia following COVID-19. Healthcare providers worldwide need to be prepared to treat post COVID-19 secondary effects on physical and mental health.

Trial registration. This project was pre-registered at OSF: https://osf.io/3e6zc. 


\section{Introduction}

\section{Background}

In March 2020, the World Health Organization (WHO) declared that Coronavirus Disease 19 (COVID-19), caused by SARS-CoV-2 infection, had reached pandemic levels. Although the symptoms of COVID-19 are highly variable across infected individuals ${ }^{1}$, sudden loss of taste and smell was quickly identified as a hallmark symptom ${ }^{2-4}$. Self-reported smell loss was shown to be useful for both diagnosis ${ }^{5-7}$ and population surveillance ${ }^{8}$, at least for SARS-CoV-2 variants common in 2020.

Classically, patient complaints of smell loss with the common cold arise from a blocked or stuffy nose that prevents volatile odorants from reaching olfactory receptors near the top of the nasal cavity, and gustation is not affected ${ }^{9}$. However, with COVID-19, sudden smell loss was commonly observed without nasal blockage ${ }^{10-12}$, and direct assessment with odor-free tastants (e.g., sugar) indicated taste was also affected ${ }^{13}$.

Most individuals (>75-80\%) reporting taste and smell impairments due to COVID-19 tend to recover these senses within a few months, but smell impairment is still reported by $25-40 \%$ of patients after one or two months ${ }^{5,14}$ at 6 months ${ }^{15,16}$. Given the common confusion between taste, smell and flavor, data on taste recovery are less clear, though suggested to recover somewhat faster than smell ${ }^{16}$. Separately, some individuals recover from acute smell loss, only to subsequently report other olfactory dysfunction, such as parosmia (smell distortions) and phantosmia (phantom smells or olfactory hallucinations) ${ }^{17,18}$.

Factors associated with persistent smell and taste dysfunction remain unknown. Some early reports suggested smell loss might be associated with a milder disease course ${ }^{19,20}$, although smell and taste impairments were also seen in severely ill patients ${ }^{21,22}$.

\section{Objectives}

The aim of this preregistered study (https://osf.io/3e6zc) was to characterize smell impairment and recovery in connection with taste loss and other symptoms, by recontacting respondents of our initial survey ${ }^{3,5}$ to collect longitudinal data in a large cohort of participants diagnosed with COVID-19.

\section{Methods}

\section{Study design}

This longitudinal, observational online cohort study entails a follow-up survey (S2) of respondents to the GCCR core survey (S1; https://www.nlm.nih.gov/dr2/COVID-19_BSSR_Research_Tools.pdf) ${ }^{3,5}$ between 2 and 10 months after initial participation. 


\section{Setting}

Participants self-selected to participate in S1. They were invited via email to participate in S2 if they previously agreed to be re-contacted, provided an email address, completed S1 in English, Spanish, Italian, Dutch, French, and reported a change in smell, taste and/or flavor (via symptom checkbox) in S1. The protocol complies with the revised Declaration of Helsinki and was approved as an exempt study by the Office of Research Protections at The Pennsylvania Study University in the U.S.A. (STUDY00014904).

\section{Participants}

\section{Eligibility criteria}

To be included in the present analysis, participants had to report a consistent COVID-19 diagnosis for both S1 and S2 - i.e., positive COVID-19 diagnosis via clinical presentation (i.e., via symptoms and history), or via viral swab, or another laboratory test. Other exclusion criteria are summarized in Figure 1.

\section{Variables, Data Sources and Measurement}

Details of the baseline variables have been described previously ${ }^{3}$. The follow-up survey collected ratings of smell and taste function on a visual analog scale, and self-reporting of parosmia and phantosmia. Other COVID-19 symptoms were collected via checklist and free text comments. Duplicate entries were removed.

\section{Bias minimization}

The survey was conducted in multiple languages to increase generalizability. Also, because participants self-selected to respond to follow-up, analysis and conclusions were restricted to individuals with COVID-19 who had chemosensory loss at disease onset. As previously noted ${ }^{5}$, focusing on this group allows for a conservative estimate of the relationship between smell dysfunction and COVID-19 diagnosis. Also, we excluded individuals with chemosensory impairment prior to COVID-19.

\section{Study size}

There was no predetermination of the study size. A pilot inquiry in English only $(n=100)$ was used to estimate feasible response rate among $\$ 1$ completers ${ }^{23}$, and invitations were sent out in the 5 languages with the greatest number of responses.

\section{Quantitative variables}

Here, S2 respondents were grouped according to whether their smell loss persisted or recovered. Participants who returned to less than $80 \%$ of their pre-COVID smell ability (as reported in S1) were categorized as smell long-haulers; the rest were classified as non 
long-haulers. Smell (taste) impairment for the two surveys were calculated for each participant using the following equations:

S1: $\left(\frac{\text { taste or smell ability during illness }}{\text { taste or smell ability pre COVID19 }}\right) \times 100$

S2: $\left(\frac{\text { current ability to taste or smell }}{\text { taste or smell ability pre COVID19 }}\right) \times 100$

The percentage of individuals with smell and taste impairments was calculated relative to the total sample $(\mathrm{N}=1,468)$.

\section{Statistical Analysis}

\section{Demographics}

To report demographics across the whole sample and to assess potential confounding variables, we calculated proportions of the presence of each of the following comorbidities: high blood pressure, heart disease, diabetes, obesity, lung disease (asthma/COPD), head trauma, neurological disease, cancer (treated with chemotherapy), cancer (no chemotherapy), chronic sinus problems, seasonal allergies/hay fever, and no condition. We also calculated the probability in each of the smell long-hauler groups. We tested distributional differences with Pearson's chi-square tests with the R base function "prop.test". We used an alpha of 0.0042 to determine significance (i.e., a Bonferroni corrected alpha of 0.05 for 12 conditions). We repeated this for language and gender distributions. For age we calculated the average and performed an independent sample t-test with an alpha of 0.05 .

\section{Differences in probability of smell distortions and other COVID-19 symptoms between participants with persistent versus recovered smell loss}

To test differences in smell distortions at the time of $S 2$ between smell long-haulers and non long-haulers, we calculated probability tables of presence and absence of parosmia and phantosmia in each of the smell long-hauler groups. We tested distributional differences with Pearson's chi-square tests with the R base function "prop.test". We used an alpha of 0.025 to determine significance (i.e., a Bonferroni corrected alpha of 0.05 for two types of distortion). We repeated this analysis for the symptoms at the time of $S 1$ to check for any pre-existing differences prior to developing persistent smell long-hauler status.

\section{Differences in symptom counts}

To assess effects of smell long-hauler-status on illness severity, we summed the presence of each of commonly listed COVID-19 symptoms (fever, dry cough, cough with mucus, difficulty breathing / shortness of breath, chest tightness, runny nose, sore throat, loss of appetite, headache, muscle aches, fatigue, diarrhea, abdominal pain, nausea, excluding smell and taste symptoms under "changes in food flavor" and "changes in smell"), leading to scores 
ranging from 0-14. Since this "count" variable was not continuous or categorical (i.e., the total number of symptoms), we used logistic regression with a Poisson distribution for the dependent variable. This was implemented via the "glm" function in R, using the "poisson" option. The assumption of equality between variance and mean of each category of the independent variable was checked ${ }^{24}$ and a "quasi-Poisson" family variant was applied if overdispersion was observed. To estimate relative risk, a Poisson regression with a robust error variance was calculated with the package Sandwich ${ }^{25-27}$.

To further characterize rare symptoms not provided in the COVID-19 symptoms checklist, additional symptoms, such as "brain fog", "memory loss", were extracted from free text comments. Comments in Spanish, Italian, Dutch, and French were translated into English by scientists who were native speakers of each language, and pooled. In total, 559 comments containing symptoms were analysed [214 French (74 men, 140 women), 195 English (54 men, 141 women), 65 Spanish (22 men, 43 women), 54 Dutch (14 men, 40 women), and 31 Italian (13 men, 18 women)].

To test for differences in overall symptoms between smell long-haulers and non long-haulers at S2, we calculated probabilities for each of the 16 symptoms (headache, fatigue, difficulty breathing/shortness of breath, diarrhoea, nausea, fever, abdominal pain, changes in food flavour, changes in smell, chest tightness, cough with mucus, dry cough, loss of appetite, muscle aches, runny nose, sore throat) in each group. As above, we tested for distribution differences, with a Bonferroni corrected alpha of 0.003125 (0.05/16 tests, one for each symptom). We repeated this analysis for $\mathrm{S} 1$ symptoms to check for preexisting differences prior to developing smell long-hauler status.

Smell ability during COVID-19 infection (measured at S1) was compared between smell long-haulers and non long-haulers (defined from S2) using a Welch's test.

\section{Results}

\section{Participants}

Participants $(n=12,313)$ who completed the initial online survey (S1) between April and September 2020 and agreed to be recontacted via email were invited to complete a follow-up survey (S2). Email invitations were sent in five languages (English: $n=3,422$, Spanish: $n=1,575$, Italian: $n=1,165$, Dutch: $n=1,840$, French: $n=4,306$ ) between September and November 2020 to those who consented to be re-contacted. Data were exported in February 2021. We received 3,386 responses (2,448 women, 927 men, 1 non-binary; age range 20 to 85 years) for S2, a response rate of $\sim 28 \%$. Of these, 1,918 participants were excluded from further analysis (see Figure 1 for details). Thus, the final dataset reported here consisted of 1,468 responses from individuals who reported smell or taste loss at baseline (S1) and reported consistent positive COVID-19 diagnoses at S1 and S2. The demographics, and overall symptoms of these individuals are reported in Table 1. 


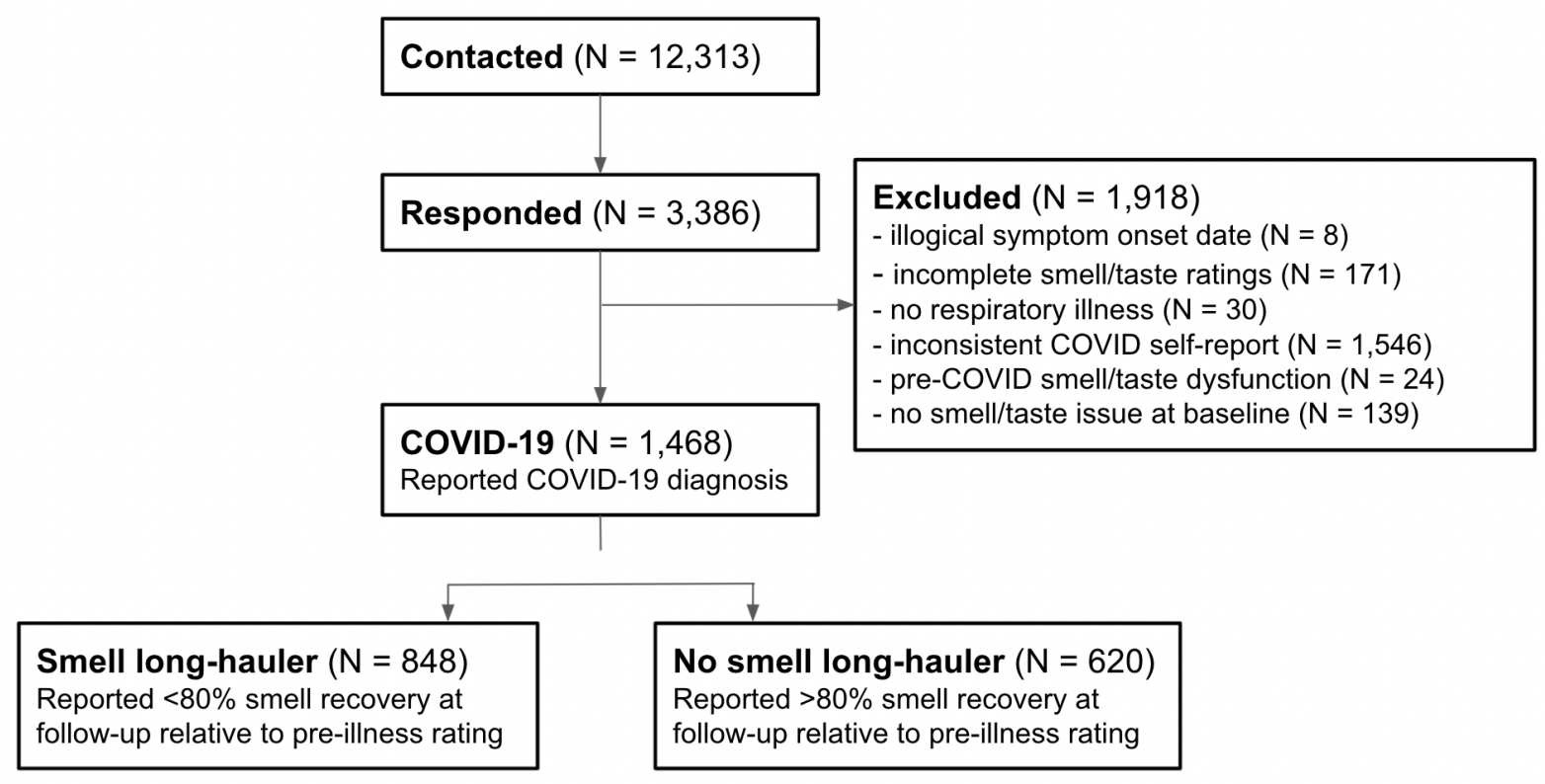

Figure 1. Summary of participants described in the current study. As shown in the exclusion box, the majority of S2 respondents were excluded from present analyses due to inconsistent reports of their COVID-19 diagnosis between S1 and S2. Participants were also excluded for missing or inconsistent data, chemosensory dysfunction prior to COVID-19.

\section{Descriptive data}

Descriptive data for all 1,468 participants are summarized in Table 1. The mean age was $\sim 44$ years, fewer men than women took part, and more responses were collected in English and French, as expected from the relative distribution of email invitations sent.

\section{Outcome data}

Time elapsed between S1 and S2 ranged from 23 to 291 days (median: 200 days) (see Supplementary Figure S1), corresponding to 36 to 326 days (median: 225 days) since disease onset; this timing enabled the calculation of cumulative rate of recovery (Table 2).

\section{Main results}

During the first months after onset of COVID-19 symptoms, less than $10 \%$ of participants reported full smell recovery, gradually increasing to $39 \%$ in women and $52 \%$ in men by up to 11 months (Table 2). Comparatively, the reports for taste recovery were greater ( $\sim 56$ to $\sim 65 \%$ by 11 months).

$58 \%$ of those in the final S2 dataset were classified as smell long-haulers (see methods), with $\sim 39 \%$ also reporting persistent taste impairment and $\sim 20 \%$ reporting recovered taste (Figure $2 \mathrm{~A}$ ). Only $\sim 3 \%$ reported impaired taste with recovered smell. This suggests smell and taste recover separately, and these sensory abilities can be distinguished by the respondents. 
medRxiv preprint doi: https://doi.org/10.1101/2021.08.28.21262763; this version posted September 8, 2021. The copyright holder for this preprint (which was not certified by peer review) is the author/funder, who has granted medRxiv a license to display the preprint in perpetuity.

It is made available under a CC-BY-NC 4.0 International license.

Qualitative disorders of smell, specifically parosmia and phantosmia, were more frequently observed at S2 (46.8\% and $24.7 \%$, respectively) than S1 $(10.2 \%$ and $10.1 \%$, respectively; Figure 2B). Further, these types of dysfunction were significantly more common in smell long-haulers than in non-long-haulers, $63.6 \%$ of smell long-haulers reported parosmia versus $23.9 \%$ of non-long-haulers $\left(X^{2}=225.0,95 \% \mathrm{Cl}=0.34-0.44, \mathrm{p}<.001, \mathrm{OR}=5.56\right)$ and $33.5 \%$ of smell long-haulers reported phantosmia versus $13.1 \%$ of non-long-haulers $\left(x^{2}=78.9\right.$, $95 \% \mathrm{Cl}=0.21-0.32, \mathrm{p}<.001, \mathrm{OR}=3.35)$. Among smell long-haulers, the incidence of parosmia was not significantly different between women and men (64\% versus $58 \%$ ). Qualitative terms from open-ended text responses were also captured. Typical participant reports for parosmia were "Some things now smell different and unpleasant" or "like chemicals"; reports for phantosmia include responses like "Sometimes I can smell burning but no one else around me can."

A

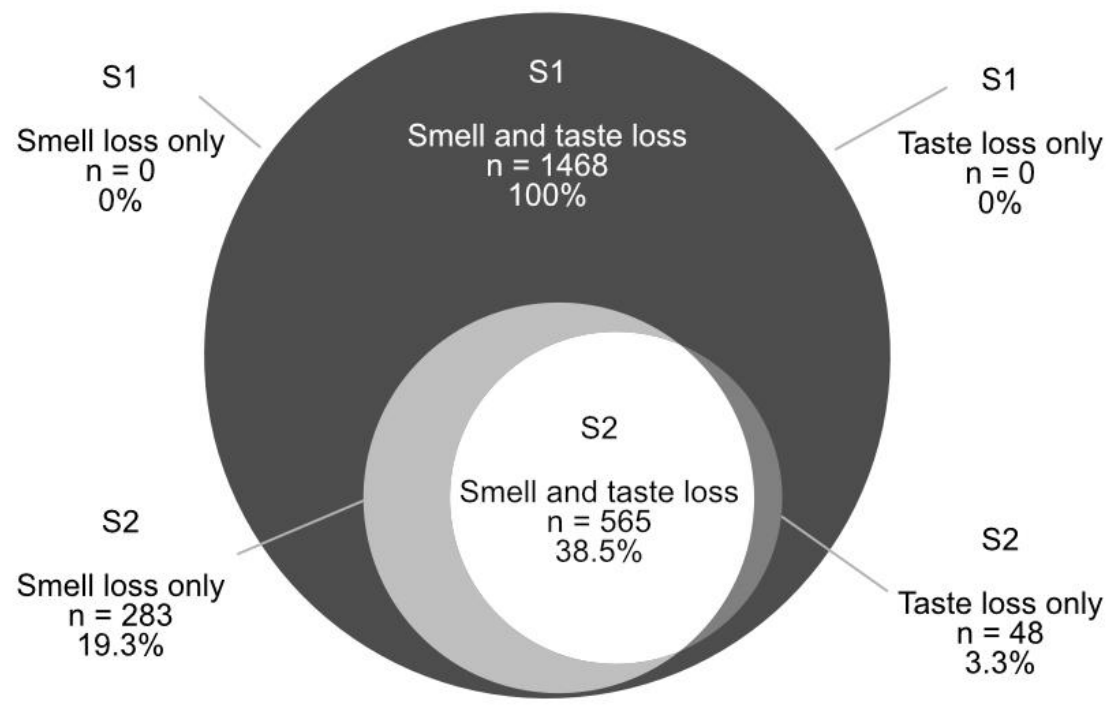

B
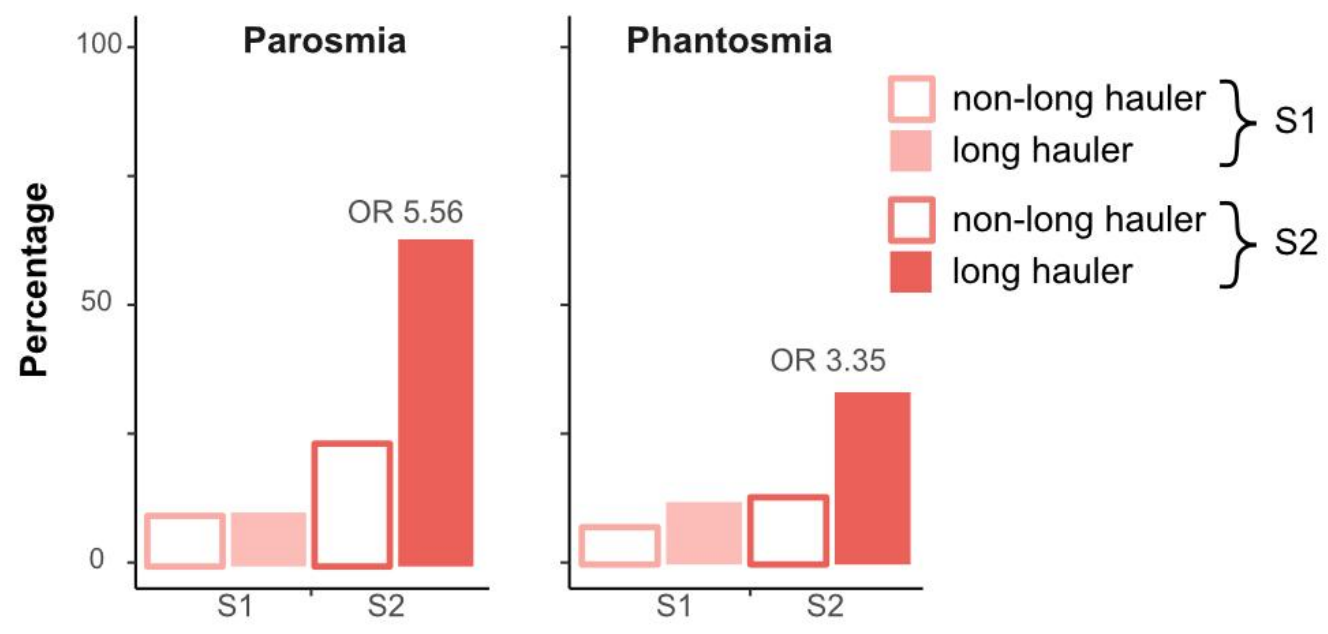
medRxiv preprint doi: https://doi.org/10.1101/2021.08.28.21262763; this version posted September 8, 2021. The copyright holder for this preprint (which was not certified by peer review) is the author/funder, who has granted medRxiv a license to display the preprint in perpetuity.

It is made available under a CC-BY-NC 4.0 International license.

Figure 2. A: Proportions of participants with smell, taste, and combined smell and taste impairments during baseline (S1, dark gray) and follow-up (S2, lighter grays and white). B: S1 (light pink) and S2 (dark pink) proportions of qualitative smell changes - specifically, parosmia and phantosmia - for individuals who will regain smell ability (white fill) or exhibit smell long-hauling (solid fill).

The total number of symptoms decreased at S2 (see Figure 3). However, smell long-haulers reported more overall symptoms (median $=1$ ) at S2 compared to non-long-haulers (median $=0)$. This was confirmed via quasi-Poisson regression $\left(\beta_{1}=0.48,95 \% \mathrm{Cl}=0.32-0.64\right.$, $\mathrm{T}=5.66, \mathrm{p}<.0001$ ). Notably, these groups were not different at $\mathrm{S} 1$ (both medians $=6$ ).

When we examine each of the symptoms, including smell and taste symptoms, we observed changes in flavor $\left(X^{2}=224.9,95 \% \mathrm{Cl}=0.37-0.46, p<.001, \mathrm{OR}=7.30\right)$ and in smell $\left(X^{2}=340.17,95 \% \mathrm{Cl}=0.44-0.53, \mathrm{p}<.001, \mathrm{OR}=10.02\right)$ as expected, in addition to other symptoms like fatigue $\left(X^{2}=22.09,95 \% \mathrm{Cl}=0.08-0.20, p<.001\right.$, OR $\left.=1.80\right)$, headache $\left(X^{2}=\right.$ $23.99,95 \% \mathrm{Cl}=0.11-0.25, \mathrm{p}<.001, \mathrm{OR}=2.24)$, and loss of appetite $\left(\mathrm{X}^{2}=33.58,95 \% \mathrm{Cl}=\right.$ $0.25-0.40, p<.001$, OR $=5.98$ ), all of which were more frequent in smell long-haulers than in non-long-haulers (Figure 3B). This suggests smell long-haulers had greater overall morbidity. Analysis of spontaneous mentions of rare symptoms in free text responses also supports the notion that smell long-haulers experience more symptoms: spontaneous comments included brain fog, hair loss, hallucination, and memory loss. Formal statistics were not applied due to low incidence of these reports (Figure 3C). 


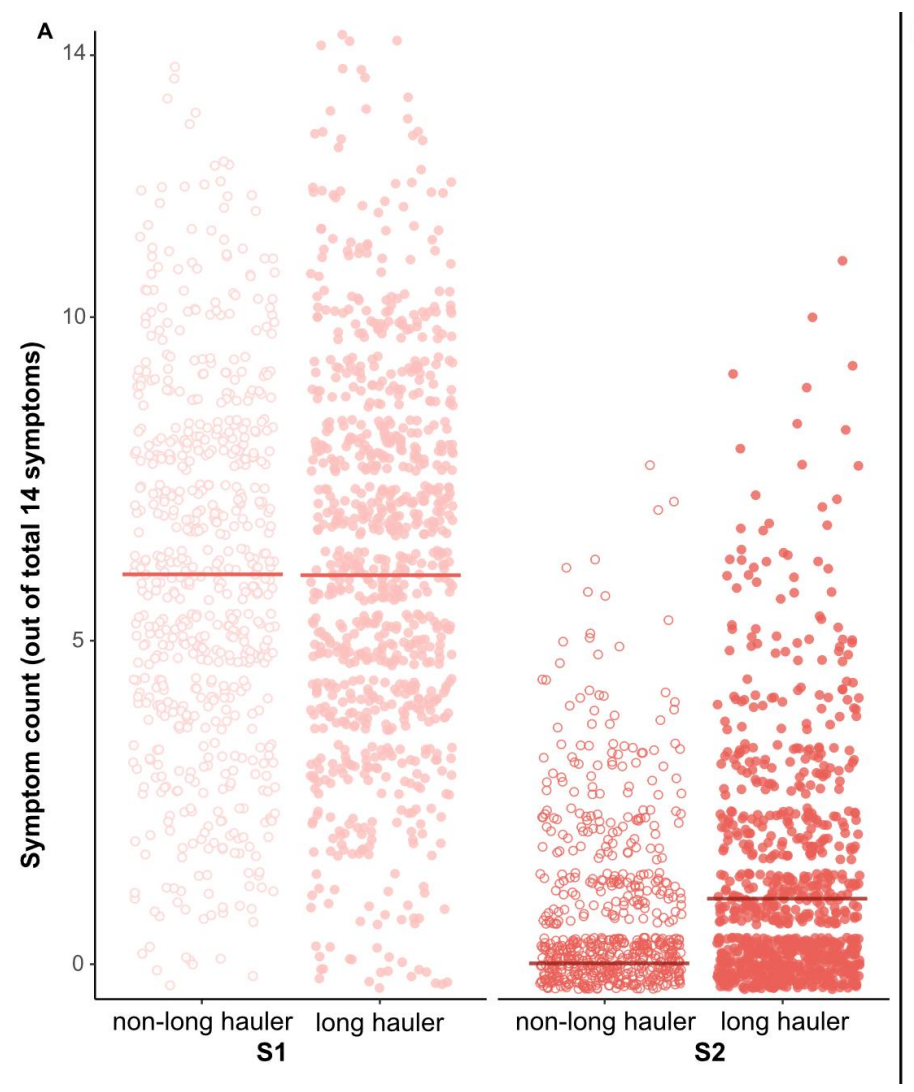

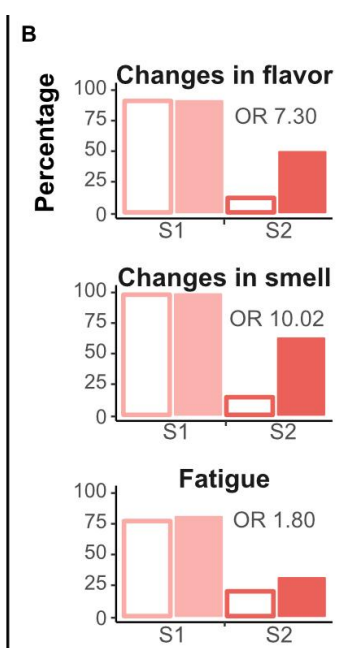
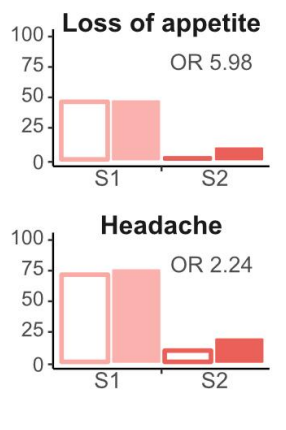
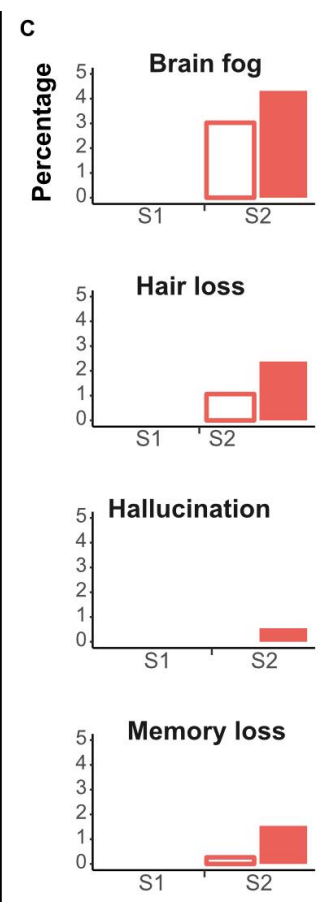

$\left.\begin{array}{l}\text { non-long hauler } \\ \text { long hauler }\end{array}\right\}$ s1 $\left.\begin{array}{l}\text { non-long hauler } \\ \text { long hauler }\end{array}\right\}$ s2

Figure 3. A: Comparison of overall number of non-chemosensory symptoms at baseline (S1, light pink) and follow-up (S2, dark pink), stratified by smell long-hauler (LH) status at S2. B: Comparison of selected symptoms at S1 and S2 stratified by smell long-haulers status at S2. C: Percentage of rare symptoms spontaneously mentioned in free text responses in English, Spanish, Dutch, Italian, and French.

To identify variables with potential prognostic value in predicting who would eventually become a smell long-hauler, we looked for differences in multiple S1 measures across the smell long-hauler and non-long-hauler groups from S2. None of these were significant, save one: the self-rated ability to smell during COVID-19 illness was slightly lower (Welch's t-test, statistic = -4.33, $p<.0001)$ in smell long-haulers $(n=848)$ than in non-long-haulers $(n=620)$, with means of $2.96( \pm 7.64,95 \% \mathrm{Cl}=2.45-3.48)$ and $5.11( \pm 10.49,95 \% \mathrm{Cl}=4.28-5.94)$, respectively. This was confirmed when the distributions of smell ability at S1 were compared by status at S2 (Kolmogorov-Smirnov test statistic $=0.12 ; p<0.0001$ ). As shown in Figure 4, a greater number of smell long-haulers rated their smell ability during illness below 5 (on a 101-point scale), relative to non-long-haulers, although the prognostic value of this small difference still needs to be confirmed. 


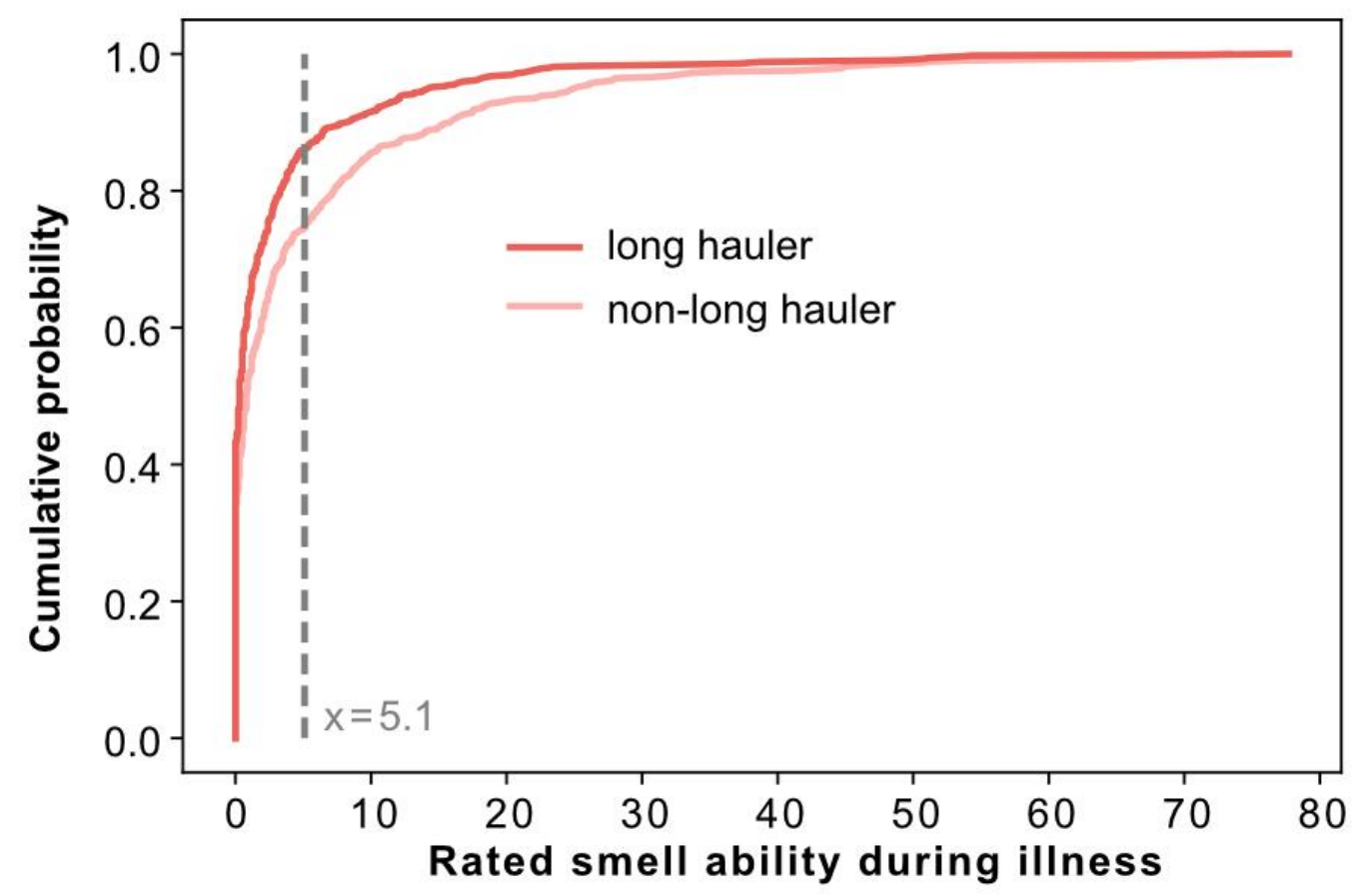

Figure 4. Distribution of ratings for smell ability at baseline (S1), stratified by whether a participant was classified as a smell long-hauler (dark pink) or non long-hauler (light pink) at follow-up (S2). At baseline, the majority of both groups (i.e., more than 50\%) show complete smell loss (a score of zero on the x-axis), but a higher proportion of those who would later recover (light pink line) were hyposmic, rather than totally anosmic, at baseline. The dashed vertical line indicates the smell ability rating (on a VAS from 0-100) where the two groups differ maximally.

Given recent work on predictors of long-COVID ${ }^{28}$, we also performed a supplementary analysis (see Supplement) on a sub-group of participants to compare the fully recovered $(\mathrm{N}=153)$ with those still experiencing at least one long-term symptom $(\mathrm{N}=202)$. The number of overall symptoms experienced during the first two weeks of the disease was predictive of having long-term symptoms. Consistent with ${ }^{28}$, the greater the number of symptoms experienced by the participants during the first 2 weeks of the disease, the more likely they were to have long-term symptoms more than 2 months later. This is also in line with more severe outcomes of hospitalized vs non-hospitalized COVID-19 patients ${ }^{29}$.

\section{Discussion}

Key results 
Our follow-up of 1482 participants suggests that $\sim 60 \%$ of women and $\sim 48 \%$ of men recover less than $80 \%$ of their pre-illness olfactory ability several months (200 days median) since COVID-19 onset. Taste recovered more quickly and rarely persisted if smell recovered. Prevalence of parosmia and phantosmia rose from $10 \%$ during the baseline survey to $\sim 47 \%$ and $\sim 25 \%$ at the follow-up. These olfactory dysfunctions were more common for smell long-haulers than non long-haulers. Persistent smell loss also coincided with more COVID-19 symptoms at follow up and a higher incidence of follow up symptoms, such as headache.

\section{Limitations}

Participants for S1 were recruited via social media (with additional coverage in traditional media) for this web-based survey which may explain why participants under 60 years of age and women are overrepresented in our sample. The $\sim 28 \%$ response rate for S2 may reflect that many S1 participants had spontaneously recovered olfactory and/or gustatory function and were therefore no longer interested in responding. The time lapse between disease onset and follow-up survey varies between participants. Furthermore, launch dates and pandemic situations varied between different countries, and time between surveys S1 and S2 differed by individuals. Despite these limitations, our findings characterize profiles of smell and taste loss recovery, with important downstream implications for public health.

\section{Interpretation}

Previously, some speculated smell loss might indicate milder COVID-19 morbidity ${ }^{20}$. Our data do not support this view; rather, we found smell long-haulers had more symptoms than recovered participants. This suggests previous under-reporting of smell dysfunction among severely ill patients may instead reflect a sampling bias; understandably it seems likely that clinicians treating critically ill patients were less focused on anosmia or parosmia as symptoms, and such patients were presumably unavailable for acute chemosensory testing.

There is important practical value in being able to predict which patients may develop long term smell loss. We found a greater reduction in the smell ability during COVID-19 illness in those who later became smell long-haulers compared to those who recovered smell ability, although this difference was numerically small. Whether the rating of smell ability during the disease can be used prognostically to predict the risk of future long-hauling needs additional exploration.

While some studies suggest self-reports may underestimate smell loss prevalence relative to direct assessment $18,30,31$, others found correlations between self-reporting and direct assessments ${ }^{32}$. Furthermore, although direct assessments have been proposed very recently ${ }^{33}$, self-report remains the current standard of care for assessment of parosmia and phantosmia ${ }^{34}$, at least until newly proposed methods can be further validated. The presence of parosmia in nearly $50 \%$ of the smell long-haulers in our sample is not surprising for post-viral olfactory dysfunction in general ${ }^{35}$. In other datasets (i.e., UK healthcare workers), parosmia is also emerging as a common sequelae of COVID-19 ${ }^{36}$. 


\section{Generalizability}

As of August 2021, there are over 36 million Americans and 210 million people worldwide recovering from COVID-19 ${ }^{37}$. According to meta-analysis ${ }^{30}, 77 \%$ of those with COVID-19 have acute smell loss when smell function is measured directly or $44 \%$ if based on self-reports. If we conservatively assume half of those with COVID-19 experience acute smell loss, this suggests $\sim 18$ million Americans may have experienced acute anosmia. If we are highly conservative and assume all of the individuals who did not respond to our follow up survey recovered, we calculate $50 \%$ (smell long haulers) of $30 \%$ (response rate), resulting in $\sim 2.7$ million Americans and $\sim 15$ millions worldwide may be smell long-haulers. Present data suggest $\sim 47 \%$ of smell long-haulers report parosmia, which would translate to over a million Americans (and over 7 million worldwide) with parosmia as a result of COVID-19.While olfactory symptoms may be formally classified as mild outcomes by some health authorities, the possibility that millions of individuals may experience long term anosmia and parosmia as a consequence of prior COVID-19 infection is highly concerning, given the downstream impacts this will likely have on dietary habits ${ }^{38}$, quality of life ${ }^{39}$, and mental health ${ }^{40}$. We also find that smell long-haulers report other post acute sequelae of COVID-19.

\section{Conclusion}

Our study provides insights on the symptoms of a large number of individuals diagnosed with COVID-19, who experienced persistent smell and taste loss, up to 11 months (6-7 months median) since disease onset. Our finding that parosmia increases from $\sim 10 \%$ at baseline to almost $50 \%$ at follow-up suggests parosmia may be a common symptom post-COVID-19. It is important that health providers, patients, and their families are aware of this potential development, and they are educated about the course of disease and management. Millions of people worldwide are likely affected and additional research as well as development of new treatment options are needed.

\section{Conflict of interest statement}

Dr. Hayes is a co-founder of Redolynt LLC. Prof. Philpott is a trustee of the charity Fifth Sense. None of the other authors have any conflicts to disclose.

\section{Acknowledgments}

We thank all members of the Global Consortium for Chemosensory Research (GCCR) for the core survey and for help with translations. We thank Danielle R. Reed and Thomas Hummel for their valuable contributions in the initial stages of this work. Deployment of the original GCCR survey and follow-up survey were both supported by an unrestricted gift from James and Helen Zallie to support sensory science research at Penn State. 


\section{References}

1. Koyama S, Ueha R, Kondo K. Loss of Smell and Taste in Patients With Suspected COVID-19: Analyses of Patients' Reports on Social Media. J Med Internet Res. 2021;23(4):e26459. doi:10.2196/26459

2. Moein ST, Hashemian SM, Mansourafshar B, Khorram-Tousi A, Tabarsi P, Doty RL. Smell dysfunction: a biomarker for COVID-19. Int Forum Allergy Rhinol. 2020;10(8):944-950. doi:10.1002/alr.22587

3. Parma V, Ohla K, Veldhuizen M G, et al. More Than Smell-COVID-19 Is Associated With Severe Impairment of Smell, Taste, and Chemesthesis. Chem Senses. 2020;45(7):609-622. doi:10.1093/chemse/bjaa041

4. CDC. Coronavirus Disease 2019 (COVID-19) - Symptoms. Centers for Disease Control and Prevention. Published February 22, 2021. Accessed July 25, 2021. https://www.cdc.gov/coronavirus/2019-ncov/symptoms-testing/symptoms.html

5. Gerkin RC, Ohla K, Veldhuizen MG, et al. Recent smell loss is the best predictor of COVID-19 among individuals with recent respiratory symptoms. Chem Senses. 2020;(bjaa081). doi:10.1093/chemse/bjaa081

6. Karni N, Klein H, Asseo K, et al. Self-rated smell ability enables highly specific predictors of COVID- 19 status: a case control study in Israel. Open Forum Infect Dis. 2020;Dec 28:ofaa589. doi:doi: 10.1093/ofid/ofaa589

7. Menni C, Valdes A M, Freidin M B, et al. Real-time tracking of self-reported symptoms to predict potential COVID-19. Nat Med. 2020;26(7):1037-1040. doi:doi: 10.1038/s41591-020-0916-2

8. Pierron D, Pereda-Loth V, Mantel M, et al. Smell and taste changes are early indicators of the COVID-19 pandemic and political decision effectiveness. Nat Commun. 2020;11(1):5152. doi:10.1038/s41467-020-18963-y

9. Dalton P. Olfaction and anosmia in rhinosinusitis. Curr Allergy Asthma Rep. 2004;4(3):230-236. doi:10.1007/s11882-004-0031-3

10. Brann DH, Tsukahara T, Weinreb C, et al. Non-neuronal expression of SARS-CoV-2 entry genes in the olfactory system suggests mechanisms underlying COVID-19-associated anosmia. Sci Adv. 2020;6(31):eabc5801. doi:10.1126/sciadv.abc5801

11. Cooper K W, Brann D H, Farruggia M C, et al. COVID-19 and the chemical senses: supporting players take center stage. Neuron. 2020;107(2):219-233. doi:doi: 10.1016/j.neuron.2020.06.032

12. Hagemann J, Onorato GL, Jutel M, et al. Differentiation of COVID-19 signs and symptoms from allergic rhinitis and common cold: An ARIA-EAACI-GA2 LEN consensus. Allergy. 2021;76(8):2354-2366. doi:10.1111/all.14815

13. Huart C, Philpott C, Konstantinidis I, et al. Comparison of COVID-19 and common cold chemosensory dysfunction. Rhinology. 2020;58(6):623-625. doi:doi: 10.4193/Rhin20.251.

14. Niklassen AS, Draf J, Huart C, et al. COVID-19: Recovery from Chemosensory Dysfunction. A Multicentre study on Smell and Taste. The Laryngoscope. 2021;131(5):1095-1100. doi:https://doi.org/10.1002/lary.29383

15. Blomberg B, Mohn KG-I, Brokstad KA, et al. Long COVID in a prospective cohort of home-isolated patients. Nat Med. Published online June 23, 2021:1-7. doi:10.1038/s41591-021-01433-3

16. Klein $\mathrm{H}$, Asseo $\mathrm{K}$, Karni $\mathrm{N}$, et al. Onset, duration and unresolved symptoms, including smell and taste changes, in mild COVID-19 infection: a cohort study in Israeli patients. Clin Microbiol Infect Off Publ Eur Soc Clin Microbiol Infect Dis. Published online February 16, 2021. doi:10.1016/j.cmi.2021.02.008

17. Watson DLB, Campbell M, Hopkins C, Smith B, Kelly C, Deary V. Altered Smell and Taste: anosmia, parosmia and the impact of long Covid-19. medRxiv. Published online November 
medRxiv preprint doi: https://doi.org/10.1101/2021.08.28.21262763; this version posted September 8, 2021. The copyright holder for this preprint (which was not certified by peer review) is the author/funder, who has granted medRxiv a license to display the preprint in perpetuity. It is made available under a CC-BY-NC 4.0 International license .

30, 2020:2020.11.26.20239152. doi:10.1101/2020.11.26.20239152

18. Vaira LA, Lechien JR, Khalife M, et al. Psychophysical Evaluation of the Olfactory Function: European Multicenter Study on 774 COVID-19 Patients. Pathogens. 2021;10(1):62. doi:10.3390/pathogens10010062

19. Iravani B, Arshamian A, Ravia A, et al. Relationship between odor intensity estimates and COVID-19 population prediction in a Swedish sample. Chem Senses. 2020;45(6):449-456. doi:https://doi.org/10.1093/chemse/bjaa034

20. Yan CH, Faraji F, Prajapati DP, Ostrander BT, DeConde AS. Self-reported olfactory loss associates with outpatient clinical course in COVID-19. Int Forum Allergy Rhinol. 2020;10(7):821-831. doi:10.1002/alr.22592

21. Amadu AM, Vaira LA, Lechien JR, et al. Analysis of the correlations between the severity of lung involvement and olfactory psychophysical scores in coronavirus disease 2019 (COVID-19) patients. Int Forum Allergy Rhinol. n/a(n/a). doi:10.1002/alr.22869

22. Cocco A, Amami P, Desai A, Voza A, Ferreli F, Albanese A. Neurological features in SARS-CoV-2-infected patients with smell and taste disorder. $J$ Neurol. 2021;268(5):1570-1572. doi:10.1007/s00415-020-10135-8

23. Parma V, Ohla K, Veldhuizen MG, et al. More Than Smell-COVID-19 Is Associated With Severe Impairment of Smell, Taste, and Chemesthesis. Chem Senses. 2020;45(7):609-622. doi:10.1093/chemse/bjaa041

24. Dean C, Lawless JF. Tests for Detecting Overdispersion in Poisson Regression Models. $J$ Am Stat Assoc. 1989;84(406):467-472. doi:10.2307/2289931

25. Zeileis A. Object-oriented Computation of Sandwich Estimators. J Stat Softw. 2006;16(1):1-16. doi:10.18637/jss.v016.i09

26. Zeileis A, Köll S, Graham N. Various Versatile Variances: An Object-Oriented Implementation of Clustered Covariances in R. J Stat Softw. 2020;95(1):1-36. doi:10.18637/jss.v095.i01

27. Zou G. A modified poisson regression approach to prospective studies with binary data. Am J Epidemiol. 2004;159(7):702-706. doi:10.1093/aje/kwh090

28. Sudre $\mathrm{CH}$, Murray B, Varsavsky $\mathrm{T}$, et al. Attributes and predictors of long COVID. Nat Med. 2021;27(4):626-631. doi:10.1038/s41591-021-01292-y

29. Lund LC, Hallas J, Nielsen H, et al. Post-acute effects of SARS-CoV-2 infection in individuals not requiring hospital admission: a Danish population-based cohort study. Lancet Infect Dis. 2021;0(0). doi:10.1016/S1473-3099(21)00211-5

30. Hannum M E, Ramirez V A, Lipson S J, et al. Objective Sensory Testing Methods Reveal a Higher Prevalence of Olfactory Loss in COVID-19-Positive Patients Compared to Subjective Methods: A Systematic Review and Meta-Analysis. Chem Senses. 2020;45(9):856-874. doi:10.1093/chemse/bjaa064.

31. Kumar AA, Lee SWY, Lock C, Keong NC. Geographical Variations in Host Predisposition to COVID-19 Related Anosmia, Ageusia, and Neurological Syndromes. Front Med. 2021;0. doi:10.3389/fmed.2021.661359

32. Lötsch J, Reichmann H, Hummel T. Different Odor Tests Contribute Differently to the Evaluation of Olfactory Loss. Chem Senses. 2008;33(1):17-21. doi:10.1093/chemse/bjm058

33. Liu DT, Welge-Lüssen A, Besser G, Mueller CA, Renner B. Assessment of odor hedonic perception: the Sniffin' sticks parosmia test (SSParoT). Sci Rep. 2020;10(1):18019. doi:10.1038/s41598-020-74967-0

34. Addison AB, Wong B, Ahmed T, et al. Clinical Olfactory Working Group consensus statement on the treatment of postinfectious olfactory dysfunction. $J$ Allergy Clin Immunol. 2021;147(5):1704-1719. doi:10.1016/j.jaci.2020.12.641

35. Philpott C, Dixon J, Boak D. Qualitative Olfactory Disorders: Patient Experiences and Self-Management. Preprints; 2020. doi:10.22541/au.159285601.19791350 
medRxiv preprint doi: https://doi.org/10.1101/2021.08.28.21262763; this version posted September 8, 2021. The copyright holder for this preprint

(which was not certified by peer review) is the author/funder, who has granted medRxiv a license to display the preprint in perpetuity.

It is made available under a CC-BY-NC 4.0 International license.

36. Lechner M, Liu J, Counsell N, et al. Course of symptoms for loss of sense of smell and taste over time in one thousand forty-one healthcare workers during the Covid-19 pandemic: Our experience. Clin Otolaryngol. 2021;46(2):451-457. doi:https://doi.org/10.1111/coa.13683

37. WHO. WHO Coronavirus Disease (COVID-19) Dashboard With Vaccination Data - United States of America. Published August 26, 2021. Accessed August 26, 2021. https://covid19.who.int

38. Postma EM, De Graaf C, Boesveldt S. Food preferences and intake in a population of Dutch individuals with self-reported smell loss: An online survey. Food Qual Prefer. 2020;79:103771. doi:10.1016/j.foodqual.2019.103771

39. Pellegrino R, Mainland JD, Kelly CE, Parker JK, Hummel T. Prevalence and Correlates of Parosmia and Phantosmia among Smell Disorders.; 2021:2021.07.02.21259925. doi:10.1101/2021.07.02.21259925

40. Yom-Tov E, Lekkas D, Jacobson NC. Association of COVID19-induced anosmia and ageusia with depression and suicidal ideation. J Affect Disord Rep. 2021;5:100156. doi:10.1016/j.jadr.2021.100156

41. Burges Watson DL, Campbell M, Hopkins C, Smith B, Kelly C, Deary V. Altered Smell and Taste: Anosmia, Parosmia and the Impact of Long Covid-19. Infectious Diseases (except HIVIAIDS); 2020. doi:10.1101/2020.11.26.20239152 


\section{Tables}

Table 1. Descriptive data of all participants and the smell long-hauler (LH) and no smell long-hauler (nLH) groups.

\begin{tabular}{|c|c|c|c|c|c|c|c|c|c|c|c|}
\hline \multirow{2}{*}{ Categorical variables } & \multicolumn{2}{|l|}{ All } & \multicolumn{2}{|l|}{ LH } & \multicolumn{2}{|l|}{$\mathrm{nLH}$} & \multicolumn{5}{|c|}{ statistics } \\
\hline & $\%$ & n & $\%$ & n & $\%$ & $\mathbf{n}$ & Chi2 & p & OR & CI lo & Cl hi \\
\hline \multicolumn{12}{|l|}{ Prior conditions } \\
\hline High blood pressure & 8.24 & 121 & 7.67 & 65 & 9.03 & 56 & $0: 71$ & 0.398 & 0.84 & -0.14 & 0.05 \\
\hline Heart disease & 0.41 & 6 & 0.59 & 5 & 0.16 & 1 & 0.73 & 0.392 & 3.67 & -0.13 & 0.64 \\
\hline Diabetes & 2.04 & 30 & 1.89 & 16 & 2.26 & 14 & 0.10 & 0.757 & 0.83 & -0.24 & 0.15 \\
\hline Obesity & 8.99 & 132 & 9.79 & 83 & 7.90 & 49 & 1.33 & 0.248 & 1.26 & -0.03 & 0.15 \\
\hline $\begin{array}{l}\text { Lung disease } \\
\text { (asthma / copd) }\end{array}$ & 5.11 & 75 & 5.31 & 45 & 4.84 & 30 & 0.08 & 0.778 & 1.10 & -0.10 & 0.14 \\
\hline Head trauma & 0.14 & 2 & 0.24 & 2 & 0.00 & 0 & 0.24 & 0.621 & Inf & 0.15 & 0.70 \\
\hline $\begin{array}{l}\text { Neurological } \\
\text { disease }\end{array}$ & 0.68 & 10 & 0.94 & 8 & 0.32 & 2 & 1.23 & 0.268 & 2.94 & -0.08 & 0.52 \\
\hline $\begin{array}{l}\text { Cancer } \\
\text { (chemotherapy) }\end{array}$ & 0.14 & 2 & 0.12 & 1 & 0.16 & 1 & 0.00 & 1.000 & 0.73 & -0.85 & 0.69 \\
\hline $\begin{array}{l}\text { Cancer (no chemo- } \\
\text { therapy) }\end{array}$ & 0.14 & 2 & 0.24 & 2 & 0.00 & 0 & 0.24 & 0.621 & Inf & 0.15 & 0.70 \\
\hline $\begin{array}{l}\text { Chronic sinus } \\
\text { problems }\end{array}$ & 4.02 & 59 & 3.42 & 29 & 4.84 & 30 & 1.52 & 0.218 & 0.70 & -0.23 & 0.05 \\
\hline $\begin{array}{l}\text { Seasonal } \\
\text { allergies/hay fever }\end{array}$ & 16.42 & 241 & 16.27 & 138 & 16.61 & 103 & 0.01 & 0.919 & 0.98 & -0.08 & 0.06 \\
\hline No conditions & 60.15 & 883 & 59.79 & 507 & 60.65 & 376 & 0.08 & 0.781 & 0.96 & -0.06 & 0.04 \\
\hline Gender & & & & & & & 18.87 & $\begin{array}{l}7.98 \mathrm{E} \\
-05\end{array}$ & & & \\
\hline women & 75.68 & 1111 & 60.85 & 676 & 39.15 & 435 & & & & & \\
\hline men & 24.25 & 356 & 48.03 & 171 & 51.97 & 185 & & & & & \\
\hline non-binary & 0.07 & 1 & 100.00 & 1 & 0.00 & 0 & & & & & \\
\hline Language & & & & & & & 30,30 & $\begin{array}{l}4,26 \mathrm{E} \\
-06\end{array}$ & & & \\
\hline Dutch & 9.13 & 134 & 64.93 & 87 & 35.07 & 47 & & & & & \\
\hline English & 37.74 & 554 & 62.27 & 345 & 37.73 & 209 & & & & & \\
\hline French & 33.65 & 494 & 47.98 & 237 & 52.02 & 257 & & & & & \\
\hline Italian & 6.81 & 100 & 66.00 & 66 & 34.00 & 34 & & & & & \\
\hline
\end{tabular}




\begin{tabular}{|l|l|l|l|l|l|l|l|l|l|l|l|l|}
\hline Spanish & 12.67 & 186 & 60.75 & 113 & 39.25 & 73 & & & & & \\
\hline & & & & & & & & & & & \\
\hline \multirow{3}{*}{ Age in years } & mean & SD & mean & SD & mean & SD & t-test & $\mathbf{p}$ & & $\mathbf{C I}$ lo & $\mathbf{C l} \mathbf{~ h i}$ \\
\hline & 43.89 & 12.17 & 44.37 & 12.16 & 43.23 & 12.18 & -1.76 & 0.078 & & -2.40 & 0.13 \\
\hline
\end{tabular}

Table 2: Cumulative percentage of participants who recovered a pre-illness ability to smell or taste by months from the onset of disease

\begin{tabular}{|l|l|l|l|l|l|l|l|l|l|l|}
\hline $\begin{array}{l}\text { Time in } \\
\text { months }\end{array}$ & 2 & 3 & 4 & 5 & 6 & 7 & 8 & 9 & 10 & 11 \\
\hline Smell & & & & & & & & & & \\
\hline Women & 0.18 & 1.26 & 2.43 & 4.05 & 6.66 & 12.69 & 27.27 & 29.43 & 35.37 & 39.15 \\
\hline Men & 0.28 & 1.68 & 3.93 & 6.17 & 9.26 & 14.88 & 35.95 & 37.92 & 45.22 & 51.96 \\
\hline Taste & & & & & & & & & & \\
\hline Women & 0.27 & 1.89 & 3.87 & 5.94 & 10.08 & 18.72 & 39.33 & 43.20 & 51.93 & 56.07 \\
\hline Men & 0.56 & 2.24 & 4.77 & 7.30 & 11.23 & 18.53 & 45.78 & 48.31 & 58.70 & 64.88 \\
\hline
\end{tabular}


medRxiv preprint doi: https://doi.org/10.1101/2021.08.28.21262763; this version posted September 8, 2021. The copyright holder for this preprint (which was not certified by peer review) is the author/funder, who has granted medRxiv a license to display the preprint in perpetuity.

It is made available under a CC-BY-NC 4.0 International license.

\section{Supplement}

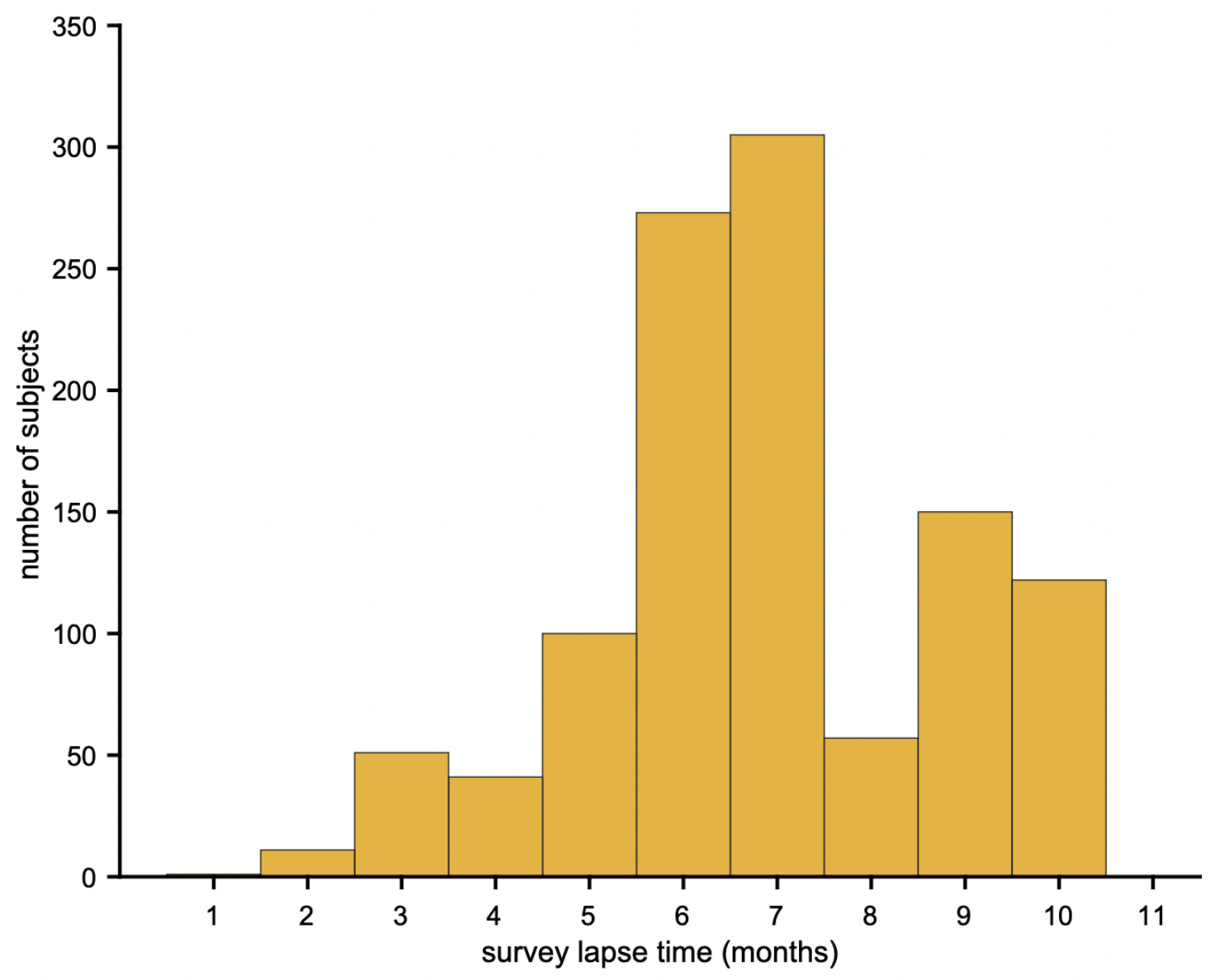

Supplementary Figure 1. Distribution of time lapse between S1 and S2. 
Supplementary Table 1. Comparison of symptoms between long haulers and non-longhaulers

\begin{tabular}{|c|c|c|c|c|c|c|c|c|c|c|c|}
\hline \multirow[b]{2}{*}{ Survey } & \multirow[b]{2}{*}{ Symptom } & \multicolumn{2}{|c|}{ longhauler } & \multicolumn{2}{|c|}{ non long hauler } & \multirow[b]{2}{*}{$\begin{array}{l}\text { Chi- } \\
\text { square }\end{array}$} & \multirow[b]{2}{*}{ P-value } & \multirow{2}{*}{\multicolumn{2}{|c|}{$\begin{array}{l}\text { P-value } \\
\text { Bonferroni Odds } \\
\text { corrected ratio }\end{array}$}} & \multicolumn{2}{|c|}{$95 \% \mathrm{Cl}$} \\
\hline & & $\%$ & $\mathbf{n}$ & $\%$ & $\mathrm{n}$ & & & & & $\begin{array}{l}\text { lower } \\
\text { bound }\end{array}$ & $\begin{array}{l}\text { higher } \\
\text { bound }\end{array}$ \\
\hline S1 & fever & $56.37 \%$ & 478 & $58.23 \%$ & 361 & 0.432 & 0.511 & & 0.93 & -0.07 & 0.03 \\
\hline s1 & dry cough & $54.48 \%$ & 462 & $56.45 \%$ & 350 & 0.486 & 0.486 & & 0.92 & -0.07 & 0.03 \\
\hline s1 & cough with mucus & $17.92 \%$ & 152 & $18.87 \%$ & 117 & 0.156 & 0.693 & & 0.94 & -0.08 & 0.05 \\
\hline $\mathrm{s} 1$ & difficulty breathing / shortness of brea & $37.85 \%$ & 321 & $36.94 \%$ & 229 & 0.093 & 0.761 & & 1.04 & -0.04 & 0.06 \\
\hline $\mathrm{s} 1$ & chest tightness & $36.79 \%$ & 312 & $32.42 \%$ & 201 & 2.824 & 0.093 & & 1.21 & -0.01 & 0.10 \\
\hline s1 & runny nose & $37.62 \%$ & 319 & $38.39 \%$ & 238 & 0.060 & 0.806 & & 0.97 & -0.06 & 0.05 \\
\hline $\mathrm{s} 1$ & sore throat & $38.09 \%$ & 323 & $33.71 \%$ & 209 & 2.787 & 0.095 & & 1.21 & -0.01 & 0.10 \\
\hline s1 & changes in food flavor & $91.04 \%$ & 772 & $91.13 \%$ & 565 & 0.000 & 1.000 & & 0.99 & -0.09 & 0.09 \\
\hline s1 & changes in smell & $98.70 \%$ & 837 & $98.23 \%$ & 609 & 0.276 & 0.599 & & 1.37 & -0.15 & 0.31 \\
\hline s1 & loss of appetite & $47.29 \%$ & 401 & $47.10 \%$ & 292 & 0.000 & 0.984 & & 1.01 & -0.05 & 0.05 \\
\hline s1 & headache & $75.00 \%$ & 636 & $71.29 \%$ & 442 & 2.340 & 0.126 & & 1.21 & -0.01 & 0.11 \\
\hline s1 & muscle aches & $63.56 \%$ & 539 & $60.81 \%$ & 377 & 1.044 & 0.307 & & 1.12 & -0.03 & 0.08 \\
\hline s1 & fatigue & $81.37 \%$ & 690 & $77.74 \%$ & 482 & 2.704 & 0.100 & & 1.25 & -0.01 & 0.12 \\
\hline $\mathrm{s} 1$ & diarrhea & $35.02 \%$ & 297 & $36.61 \%$ & 227 & 0.328 & 0.567 & & 0.93 & -0.07 & 0.04 \\
\hline s1 & abdominal pain & $18.40 \%$ & 156 & $14.68 \%$ & 91 & 3.278 & 0.070 & & 1.31 & 0.00 & 0.13 \\
\hline s1 & nausea & $26.42 \%$ & 224 & $22.26 \%$ & 138 & 3.111 & 0.078 & & 1.25 & -0.01 & 0.11 \\
\hline S2 & fever & $0.71 \%$ & 6 & $0.49 \%$ & 3 & 0.039 & 0.843 & & 1.46 & -0.28 & 0.45 \\
\hline s2 & dry cough & $6.49 \%$ & 55 & $4.38 \%$ & 27 & 2.640 & 0.104 & & 1.52 & -0.01 & 0.21 \\
\hline S2 & cough with mucus & $4.72 \%$ & 40 & $3.08 \%$ & 19 & 2.085 & 0.149 & & 1.56 & -0.03 & 0.23 \\
\hline S2 & difficulty breathing / shortness of brea & $10.39 \%$ & 88 & $6.81 \%$ & 42 & 5.228 & 0.022 & 0.356 & 1.59 & 0.02 & 0.20 \\
\hline s2 & chest tightness & $6.26 \%$ & 53 & $6.32 \%$ & 39 & 0.000 & 1.000 & & 0.99 & -0.11 & 0.10 \\
\hline s2 & runny nose & $7.91 \%$ & 67 & $4.54 \%$ & 28 & 6.145 & 0.013 & 0.211 & 1.81 & 0.03 & 0.24 \\
\hline S2 & sore throat & $4.25 \%$ & 36 & $3.08 \%$ & 19 & 1.049 & 0.306 & & 1.40 & -0.06 & 0.22 \\
\hline S2 & changes in food flavor & $49.47 \%$ & 419 & $11.83 \%$ & 73 & 224.940 & 0.000 & 0.000 & 7.30 & 0.37 & 0.46 \\
\hline S2 & changes in smell & $62.81 \%$ & 532 & $14.42 \%$ & 89 & 340.170 & 0.000 & 0.000 & 10.02 & 0.44 & 0.53 \\
\hline S2 & loss of appetite & $8.97 \%$ & 76 & $1.62 \%$ & 10 & 33.580 & 0.000 & 0.000 & 5.98 & 0.25 & 0.40 \\
\hline S2 & headache & $18.54 \%$ & 157 & $9.24 \%$ & 57 & 23.990 & 0.000 & 0.000 & 2.24 & 0.11 & 0.25 \\
\hline S2 & muscle aches & $11.69 \%$ & 99 & $8.27 \%$ & 51 & 4.180 & 0.041 & 0.654 & 1.47 & 0.01 & 0.17 \\
\hline S2 & fatigue & $31.40 \%$ & 266 & $20.26 \%$ & 125 & 22.090 & 0.000 & 0.000 & 1.80 & 0.08 & 0.20 \\
\hline S2 & diarrhea & $4.84 \%$ & 41 & $2.76 \%$ & 17 & 3.550 & 0.060 & & 1.80 & 0.00 & 0.26 \\
\hline S2 & abdominal pain & $4.96 \%$ & 42 & $4.38 \%$ & 27 & 0.156 & 0.693 & & 1.14 & -0.09 & 0.16 \\
\hline S2 & nausea & $5.43 \%$ & 46 & $3.24 \%$ & 20 & 3.483 & 0.062 & & 1.71 & 0.00 & 0.25 \\
\hline
\end{tabular}

\section{Differences in smell changes between COVID-19 antibody test results}

Participants were asked whether they have been tested for the COVID-19 antibody at the follow-up. Among participants who had consistent COVID-19 diagnosis (1,471 positive and 913 negative), 1,064 and 203 reported having positive $(A b+)$ and negative $(A b-)$ antibody test results, respectively, with the remaining reporting no antibody test $(n=1100)$ or unknown $(n=17)$. We conducted a t-test to assess the difference in the self-report ability to smell between $\mathrm{Ab}+$ and $\mathrm{Ab}$ - at four time points, which were before illness, during illness, most impaired and current. We showed that participants with $\mathrm{Ab}+$ had lower ratings of smell during illness and at the most impaired period (Supplementary Figure 2). There were no differences before illness and at the current time. These results were consistent with our previous study comparing the ratings of smell between participants who were diagnosed with COVID-19 + and COVID-19 -, providing additional support for the reduced olfactory function in COVID-19. 


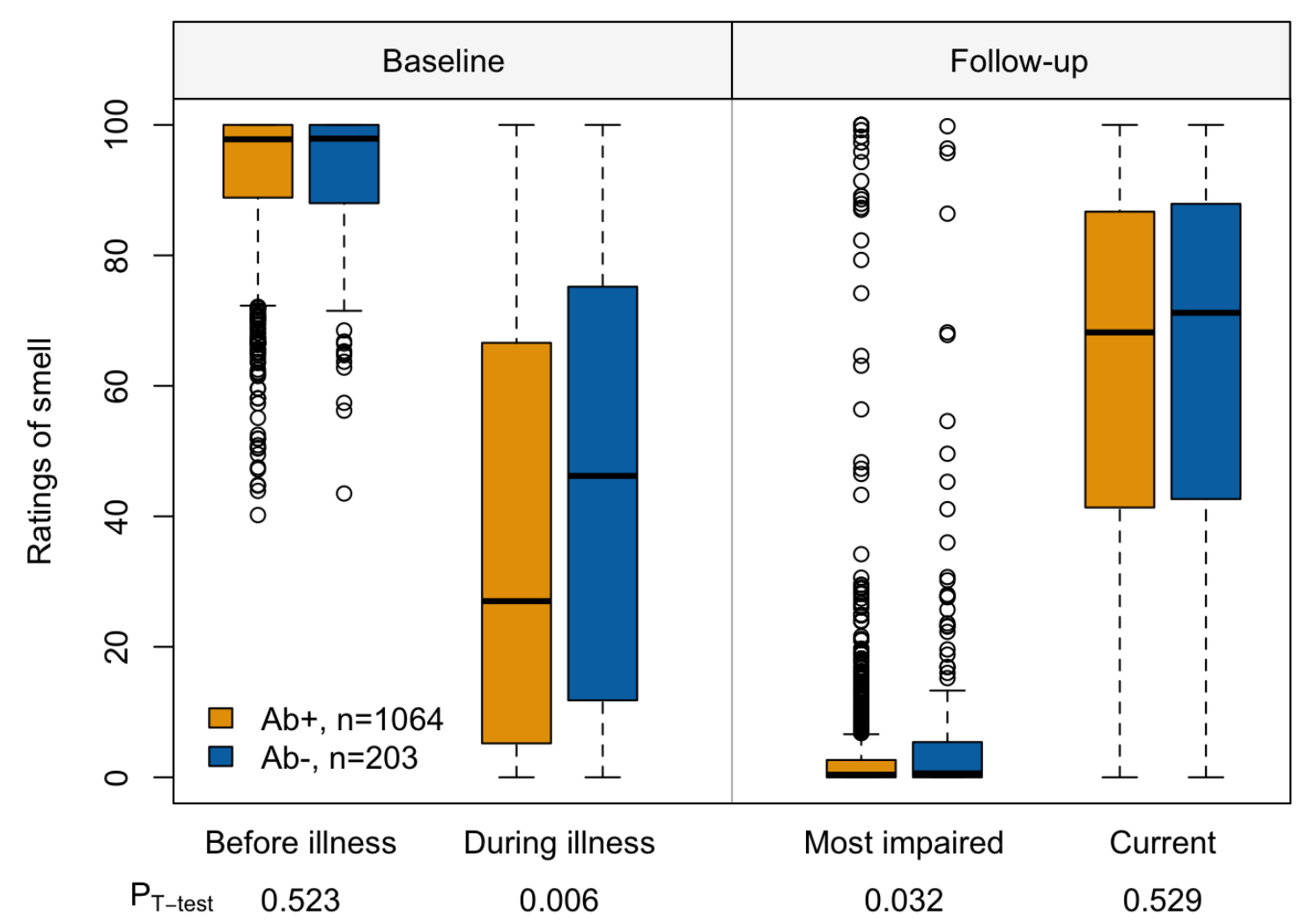

Supplementary Figure 2. Comparison of self-report ability to smell between individuals who tested positive $(\mathrm{Ab}+)$ and negative (Ab-) for the COVID-19 antibody. Ratings before illness and during illness were collected at the baseline and most impaired and current ratings were collected at the follow-up.

Is the number of symptoms experienced during the first two weeks of illness predictive of long-COVID?

\section{Participants}

To examine whether the number of symptoms experienced during the first two weeks of illness is predictive of long-COVID, we performed analyses on a separate sub-group of recontacted participants, namely COVID-19 positive participants who responded both to S1 during the first 14 days of illness and to $S 2$ more than 2 months ( $\geq 61$ days) after disease onset. From this sub-group ( $\mathrm{N}=355$ ), we categorized participants according to their disease status at $\mathrm{S} 2$ : those who reported to still experiencing at least 1 symptom more than 61 days after the disease onset were defined as 'Long-COVID' ( $\mathrm{N}=202,161$ women, 41 men) while those who reported 0 symptom were defined as 'Recovered' ( $N=153,104$ women, 49 men). 


\section{Statistical analyses}

We used a logistic regression (glm function with a binomial error structure of the stats package in $\mathrm{R}$ ) to assess whether the two categories of participants (Long-COVID vs Recovered) differed in terms of overall number of symptoms they respectively experienced during the first two weeks of disease. Our dependent variable was the "Participants' category" (Long-COVID vs Recovered). Our explanatory variable was the "Number of symptoms" reported during the first two weeks. We also included "Age" and "Gender" as control variables. Finally, we added the variable 'Time-lapse' corresponding to the number of days between disease onset and the date of S2 completion as a control variable. In other words, the model was: Participants' category Number of symptoms + Age + Gender + Time-lapse. We centred Age and Time-lapse in order to make the effects more easily biologically interpretable. The significance of each variable was tested with likelihood ratio tests comparing the full model to those without the term of interest and the $\alpha$-level was set to 0.05 .

\section{Results}

The logistic regression revealed a significant effect of the number of symptoms during the first 14 days of disease $(B=0.10, \mathrm{SE}=0.04,95 \% \mathrm{Cl}=1.032-1.196, \chi 2=7.98, p=.005, \mathrm{OR}=1.11)$ : participants who developed long-COVID (i.e., they are still experiencing at least one symptom after 61 days) experienced a significantly higher number of symptoms (Mean $\pm S D=8.3 \pm 3.07$ symptoms) during the first 14 days of disease compared to the participants who had fully recovered after two months (Mean $\pm \mathrm{SD}=7.3 \pm 2.87$ symptoms). Importantly, the number of days between disease onset and S2 completion does not significantly differ between the two categories of participants $\left(B=-0.001, \mathrm{SE}=0.002,95 \% \mathrm{Cl}=0.995-1.003, \chi^{2}=0.24, \mathrm{p}=.62\right.$, OR $=1.00)$. No significant effect of age $(B=0.02, S E=0.009,95 \% \mathrm{Cl}=0.997-1.036, X 2=2.84, p$ $=.09, \mathrm{OR}=1.02)$ or gender $(\beta=0.46, \mathrm{SE}=0.25,95 \% \mathrm{Cl}=0.961-2.612, \mathrm{X} 2=3.25, \mathrm{p}=.07, \mathrm{OR}=$ 1.58) was found.

In summary, these findings indicate that the greater the number of symptoms COVID-19 patients experienced during the first 2 weeks of illness, the more likely they are to have long-term symptoms, which is in line with previous findings ${ }^{41}$. This is also in line with more severe outcomes of hospitalized versus non-hospitalized COVID-19 patients ${ }^{29}$. 